\title{
Shifting Entrepreneurial Thinking Into High Gear
}

\author{
mark spriggs (University of St. Thomas)
}

Students and teachers can use the Business Model Canvas to describe, organize and design a business model for an entrepreneurial venture or a business development opportunity in an existing business. The fictitious case described below is the basis of a useful exercise. It can be used alone, with Osterwalder's Business Model Generation text, or with other resources explaining the Business Model Canvas.

\section{The Case}

Brian stood in his garage; he had finally bought the car he had dreamed of since he started driving. He was now the proud owner of a BMW Z3, just like the one James Bond drove in Golden Eye. Introduced in in 1994, it was the first mass production roadster in almost 20 years, following the demise of the Triumph and MG two-seat British roadsters in the mid 1970s. When he was 17, Brian had wanted to buy a friend's TR3A, but his parents said no. He could still recall the feeling of driving that car: top down, and so low to the ground you could scrape your knuckles on the pavement. Now after many years of dreaming, he had his roadster.

But when Brian's 20-year-old son Steven came home from college, he saw the car and said, "Wow...I need to learn to drive a stick shift." Brian's initial reaction was dread. Learning how to use a clutch was not easy - let it out too fast, and the car lurches forward and kills the engine. Too slow, and you run the risk of burning out the clutch. Furthermore, knowing when to shift gears was complicated. You had to watch or listen to the engine RPMs to shift to the next gear. Downshifting was tricky too, as it required balancing engine RPMs and releasing the clutch correctly to achieve a smooth shift and to protect the transmission, clutch and tires. Brian wasn't sure he had the patience to teach Steven, or that he wanted to subject his car to wear and abuse while his son learned to master the manual transmission. But he had an idea. Maybe I can send him to driving school.

Brian started researching if any driving schools offered manual transmission lessons and instruction. A few schools scattered across the country did offer instruction, as did the high-performance driving schools (e.g., Ferrari), but it was not available anywhere nearby.

As he thought about it more, Brian wondered if this might be a viable business idea. Faced with the prospect of damage to his car while his son is learning to operate a clutch and shift a transmission, Brian wonders if his son could master this skill another way, one that didn't involve driving his beloved new possession. But was there a market for a manual transmission driving school?

That led to other questions. Were there any manual transmission driving simulators or would learners have to use a real car? How long would it take for people to learn the basics? Achieve mastery? What certifications would the instructor need? When are drivers capable of and/or interested in learning to drive a manual transmission -- at 16? 21 ? 30? When they buy their first manual transmission? How big is the market? What about existing and potential competitors? Barriers to entry? Operational costs?

The business idea in this case emerges from Brian's desire to protect his recently acquired sports car from his son's desire to learn to drive a manual transmission. The time was right for Brian personally; he was bored in his current job and had been considering starting his own business. He thought he could start small, work on it in his spare time, possibly expand or grow it, and eventually sell it to finance his retirement. Is a driving school that teaches stick shift a sound business idea?

\section{Teaching Purpose}

- Explain the nine building blocks of the Business Model Canvas

- Use the Business Model Canvas as a tool to communicate and coordinate the business development process

- Understand how hypothesis testing is used to refine or 'pivot' the idea

\section{Discussion}

Do you remember learning to drive a manual transmission and/or teaching someone else to drive a 
manual transmission? What was your experience?

\section{The Clutch:}

- Learning how much and how fast to let the clutch out to start the car moving

- How to keep from rolling back on a hill

- Remembering to push in the clutch when stopping

The Shifter:

- Avoiding grinding the gears

- Knowing the shift pattern

- Putting it in the wrong gear

- Understanding the difference between upshifting and down-shifting

The Engine:

- Knowing when to shift gears based on RPM's (with or without tachometer)

- Remembering to depress the clutch before starting the car

What are your concerns about learning to drive a manual transmission, or teaching someone else?

- Damage to the car/transmission

- Safety: learning to drive in traffic can be unsafe; e.g., lurching into intersection

- Damage to the relationship between teacher and student

Who may be interested in learning to drive a manual transmission?

- Newly licensed drivers

- People learning to drive

- Drivers interested in buying a manual transmission car

- Sports/Performance car owners/buyers

- Valets

- Commercial Truck Drivers

Based on these concerns and potential customers, what could be a value proposition for this business? (The value proposition could be the same for all customers or a bit different for individual segments.)
- Helping you learn to drive a manual transmission safely.

- Training you to be a complete driver; able to drive any car or truck.

- Teaching you to drive the car you always dreamed of owning.

- Expanding your driving possibilities.

- Learn to drive a manual transmission without harming the car or your friendships.

If it wasn't assigned prior to class, show the Alexander Osterwalder Business Model Canvas video here, (See link below) and fill in the Value Proposition and Customer Segments segments. (If you have a projector and white board, you can project the blank canvas on the Board and complete the various building block sections.)

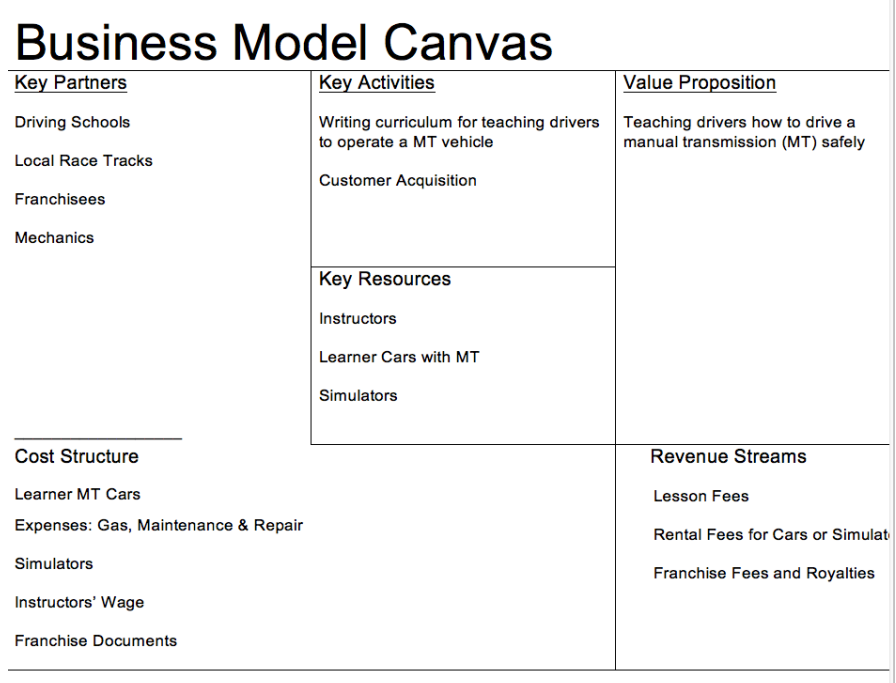

\section{Teaching the Case}

I start with a general discussion about learning to drive a manual transmission. The class usually has people who can drive a manual transmission, and a few who have taught others to drive one as well. I ask them about their experience: why did you decide to learn, how long had you been driving before learning, how and where did you learn, who owned the car, and what was the hardest part. I attempt to get at both the mechanical aspects as well as the emotional issues of safety, stress on the relationship with the person teaching them, and other concerns they had at the time.

Next I ask students to generate a list of people who may want to learn to drive a manual transmission, building on what students shared in their personal experience plus 
other potential customers like valets or truck drivers. Once these two areas are developed, I move to the Business Model Canvas, filling in the Customer Segment section, then work on the Value Proposition.

You can use one VP for the canvas, or, since there are several different types of customers with different needs, you can develop a separate canvas for each type of customers. One way to use this in class is to have groups of students develop a canvas for a specific customer, and then discuss commonalities after each group brings their canvas back to the group. At some point I develop a central canvas integrating the different parts of the business model.

After development of a canvas (or set of canvases), I point out that everything on the canvas is a hypothesis; the next step is to research the statements on the canvas by talking to potential customers and partners, and doing other research to either confirm or refute the hypotheses on the canvas. For the refuted hypotheses, new ones are created that modify the business model. This is a pivot; changing from what is not true and would create problems for the business idea, to something else that is true and will help the business be successful at attracting and keeping customers.

For example, you may believe that valet company owners will pay for their valets to learn to drive a manual transmission. But after you interview valet company owners, you conclude the owners expect their employee/valets to already know how to drive a manual or expect the valets to sign up and pay for the lessons on their own. That changes your customer segment and other parts of your model like your customer acquisition strategy, or the price you can charge.

The main point is that a plan that incorporates customer feedback and changes during the business development process has a higher likelihood of success than a more traditional business plan development process that focuses on writing the complete plan before getting feedback from customers to test the components of the business plan.

I finish with a summary of the role the Business Model Canvas can play in the business development process -- an organizing framework, a communication tool, and a roadmap that increases the likelihood of success for the business.

\section{Resources:}

\section{Business Model Canvas}

Alexander Osterwalder - Short Video on BMC

https://www.youtube.com/watch?v=2FumwkBMhLo

Strategyzer

http://www.businessmodelgeneration.com/canvas/bmc

\section{Regional Driving Schools}

The Next Street

https://www.thenextstreet.com/ct-driving-schoolsservices/manual-stick-shift-training

\section{Driving Simulators}

\section{SimURide}

http://www.amazon.com/Driving-Simulator-SIMURIDEautomatic-transmission-PC/dp/B00119MXVI

Virage Simulators

http://viragesimulation.com/vs500m-car-simulatortraining-and-research/

Additional Search Terms: entrepreneurship courses, teaching ideas, teaching resources, classroom ideas, entrepreneurship classes, business schools, business school classes, entrepreneurship students, professors 